\title{
Detecting Early Pancreatic Cancer: Current Problems and Future Prospects
}

Hiroyuki Matsubayashi ${ }^{1,2}$, Hirotoshi Ishiwatari $^{1}$, Keiko Sasaki $^{3}$, Katsuhiko Uesaka $^{4}$, and Hiroyuki Ono ${ }^{1}$ Divisions of ${ }^{1}$ Endoscopy, ${ }^{2}$ Genetic Medicine Promotion, ${ }^{3}$ Pathology, and ${ }^{4}$ Hepato-Biliary-Pancreatic Surgery, Shizuoka Cancer Center, Shizuoka, Japan

The number of patients with pancreatic cancer $(\mathrm{PC})$ is currently increasing in both Korea and Japan. The 5-year survival rate of patients with PC 13.0\%; however, resection with minimal invasion (tumor size: $\leq 10 \mathrm{~mm}$ ) increases the 5-year survival rate to $80 \%$. For this reason, early detection is essential, but most patients with early-stage PC are asymptomatic. Early detection of PC has been reported to require screening of high-risk individuals (HRIs), such as those with a family history of PC, inherited cancer syndromes, intraductal papillary mucinous neoplasm, or chronic pancreatitis. Studies on screening of these HRIs have confirmed a significantly better prognosis among patients with PC who were screened than for patients with PC who were not screened. However, to date in Japan, most patients with early-stage PC diagnosed in routine clinics were not diagnosed during annual health checks or by surveillance; rather, PC was detected in these patients by incidental findings during examinations for other diseases. We need to increase the precision of the PC screening and diagnostic processes by introducing new technologies, and we need to pay greater attention to incidental clinical findings. (Gut Liver 2020;14:30-36)

Key Words: Pancreatic neoplasms; Early detection of cancer; Risk factors; Mass screening; Incidental finding

\section{INTRODUCTION}

The number of patients with pancreatic cancer (PC) is currently increasing in both Korea and Japan. At present, the nationwide cancer death due to PC for the Japanese population is over 30,000 per year and PC ranks 4th among all human cancers. The overall 5-year survival for patients with PC is only $13.0 \%$; however, this survival can increase to $80.4 \%$ if $\mathrm{PC}$ is treated when the tumor size is $\leq 10 \mathrm{~mm}$ or it can increase to $85.8 \%$ when PC is treated at Union for International Cancer Control (UICC)-stage $0 .{ }^{1}$ For these reasons, early detection is essential to cure this deadly cancer. However, most patients with early stages of PC are asymptomatic; consequently, PC tends to be diagnosed only at advanced stages, when symptoms have become apparent. ${ }^{1,2}$

One strategy for detecting early PC is to follow high-risk individuals (HRIs), and diagnose and resect their tumors at a suitable time. At present, many studies have focused on surveillance of groups at high risk for PC. Information about PC actually diagnosed at the early stage is now being accumulated.

\section{SURVEILLANCE OF HIGH-RISK GROUPS FOR PC}

\section{Risk factors for PC}

Several pancreatic diseases, including intraductal papillary mucinous neoplasm (IPMN), ${ }^{3-5}$ pancreatic cysts, main pancreatic duct (MPD) dilation, ${ }^{6}$ and chronic pancreatitis, ${ }^{7,8}$ are risk factors for PC. Other risk factors include inherited factors (family history of $\mathrm{PC},{ }^{9,10}$ several inherited cancer syndromes, ${ }^{9}$ hereditary pancreatitis [HP],,$^{8,11,12} \mathrm{ABO}$ blood type ${ }^{13-15}$ ) and lifestyle factors (obesity, ${ }^{16-18}$ smoking, ${ }^{19-21}$ and diabetes mellitus ${ }^{20,22,23}$ ) (Table 1). The risk of a single lifestyle factor is modest, but the risk level increases with multiple factors or with additional conditions. For instance, individuals with a family history of PC, smoking, and diabetes have odds ratio increases of up to $10 .{ }^{20}$ Individuals with diabetes have a relative risk (RR) of long-standing disease of approximately $2 ;^{20,23}$ however, if consideration is limited to newonset cases ( 3 years since initial diagnosis), the RR increases to $8 .^{23}$

Approximately $2 \%$ to $3 \%$ of cases with branch-type IPMN will undergo malignant transformation every year, ${ }^{24,25}$ and a concomitant PC can develop at an annual rate of $0.7 \%$ to $2 \%{ }^{3,5,26,27}$ A recent meta-analysis by Choi et al. ${ }^{4}$ demonstrated a

\footnotetext{
Correspondence to: Hiroyuki Matsubayashi

Division of Endoscopy and Genetic Medicine Promotion, Shizuoka Cancer Center, 1007 Shimonagakubo, Nagaizumi, Suntogun, Shizuoka 4118777, Japan

Tel: +81-55-989-5222, Fax: +81-55-989-5692, E-mail: h.matsubayashi@scchr.jp Received on November 5, 2018. Revised on January 5, 2019. Accepted on January 25, 2019. Published online April $23,2019$. pISSN 1976-2283 eISSN 2005-1212 https://doi.org/10.5009/gnl18491

(a) This is an Open Access article distributed under the terms of the Creative Commons Attribution Non-Commercial License (http://creativecommons.org/licenses/by-nc/4.0) which permits unrestricted non-commercial use, distribution, and reproduction in any medium, provided the original work is properly cited.
} 
difference in the cumulative risk of PC between low-risk IPMN (lesions without MPD involvement or mural nodules) and highrisk IPMN; that is, $0.02 \%$ at 1 year, $3.1 \%$ at 5 years, and $7.8 \%$ at 10 years for low-risk IPMN versus 2.0\% at 1 year, 9.8\% at 5 years, and $24.7 \%$ at 10 years for high-risk IPMN. The hazard ratio (HR) and 5-year cumulative risk of PC in cases with mild MPD dilation were reported as 3.8\% and 1.8\%, respectively, while cases with an additional pancreatic cyst lesion had HR and 5-year cumulative risks that increased to $27.5 \%$ and 5.6\%, respectively. ${ }^{6}$

The RR of PC in cases of chronic pancreatitis was reported as $13.3^{8}$ to $16.2^{28}$ in the early period after the initial diagnosis; however, the RR diminished as the observation period increased (RR: 16.2 at the first 2 years, 7.9 at 5 years, and 3.5 at 9 years). ${ }^{8}$ Over a 20 -year period, PC developed in $\leq 5 \%$ of conventional chronic pancreatitis patients. ${ }^{8,29}$ These results may suggest the possibility of overlooking or misdiagnosing $\mathrm{PC}^{28}$ so that they many not reflect the actual risk shown by the RR value. Typically, PC is pathologically confirmed in $7.1 \%{ }^{30}$ of the resected pancreases clinically diagnosed with chronic pancreatitis, and the incidence is further increased to $27.8 \%$ in cases where malignant transformation is suspected preoperatively. ${ }^{31}$ For this reason, the need for long-term PC screening of patients with chronic pancreatitis remains controversial, ${ }^{8}$ but patients with

Table 1. Known Risk Factors for Pancreatic Cancer

\begin{tabular}{ll}
\hline \multicolumn{1}{c}{ Risk factor } & \multicolumn{1}{c}{ Risk level } \\
\hline IPMN & SIR: 16.7 \\
Pancreatic cyst & SIR: 22.5 , HR: 6.2 \\
Main pancreatic duct dilation & HR: 6.4 \\
Chronic pancreatitis & RR: $2.9-13.3$ \\
Diabetes & RR: 1.9 \\
Obesity & RR: $1.4-2.6$ \\
Smoking & RR: $1.2-1.7$ \\
Blood type (A, B, AB $>0)$ & RR: $1.3-1.4$, OR: $1.3-1.5$ \\
Family history of PC & SIR: $4.5-32^{*}$ \\
\hline
\end{tabular}

IPMN, intraductal papillary mucinous neoplasm; SIR, standardized incidence ratio; HR, hazard ratio; $\mathrm{RR}$, relative risk; OR, odds ratio; PC, pancreatic cancer.

*The risk correlates with the number of PC patients in the family. specific subtypes of chronic pancreatitis, such as $\mathrm{HP}^{11}$ and tropical pancreatitis (TP) ${ }^{32}$ have very high PC risk (RR, $69.0 ;^{8}$ lifetime risk, $40 \%$ to $55 \%$ for $\mathrm{HP} ;^{33} \mathrm{RR}, 100$ for $\mathrm{TP}^{32}$ ).

Pancreatic duct stenosis and focal or upstream parenchymal atrophy ${ }^{34}$ are the findings that are now attracting attention, as they are sometimes accompanied by occult or small PCs. ${ }^{2}$

\section{Annual health check system in Japan}

The Industrial Safety and Health Law requires that all companies in Japan ensure that their employees undergo an annual medical health check, with the aim of health maintenance and promotion by detecting asymptomatic diseases, including cancers. Cancer screening is divided into population-based screening and opportunistic screening. The five most effective cancer screenings in Japan, as confirmed by their mortality-reducing effects, are population-based screenings (http://canscreen.ncc. go.jp/index.html) ${ }^{35}$ (Table 2), but screening for PC generally involves only opportunistic screening.

During the basic annual health check, abdominal ultrasonography (US) reveals abnormal pancreatic findings in about $2 \%$ of the population examined in Japan. These findings include pancreatic cysts (1.0\%), dilation of the MPD (0.6\%), and pancreatic masses (0.1\%). The addition of further examinations results in detection of a PC in only $0.007 \%$ of the total examined population. ${ }^{36}$ During these screenings, the entire abdominal US must be completed within 10 minutes per examinee, and most cases (92\%) have non-visualized blind spots, such as the pancreas tail portion, where visualization is hindered by the left costal bone, and the pancreas head portion, where visualization is influenced by intestinal gas. ${ }^{36}$ The resulting detection rates, which are further complicated by the lack of examination accuracy, are significantly inferior to those obtained for population-based screenings of other organs in Japan (Table 2).

Some of the health check centers in Japan are now doing US screening that focuses on the pancreas in an attempt to improve the efficacy and precision of diagnoses. ${ }^{37,38}$ The targets of these centers are patients at high risk for PC, especially those with pancreatic duct dilation and cysts. The screeners spend more than 20 minutes per case for the pancreas examination alone and reduce blind spots by rotation and elevation of the examinee's upper body and by having the patient drink tea to fill

Table 2. Cancer Detection by Population-Based Screening in Japan

\begin{tabular}{|c|c|c|c|c|}
\hline Cancer type & No. of examinee & Modality of 1st examination & Rate of 2nd examination, \% & Cancer incidence, No. (\%) \\
\hline Lung cancer & $3,348,270$ & X-ray, sputum cytology & 1.98 & $1,548(0.05)$ \\
\hline Colorectal cancer & $2,535,814$ & Fecal occult blood & 6.05 & $3,868(0.15)$ \\
\hline Gastric cancer & $2,242,063$ & Barium meal & 6.76 & $2,731(0.12)$ \\
\hline Cervical cancer & $1,291,279$ & Cervical cytology & 1.40 & $166(0.01)$ \\
\hline Breast cancer & $1,282,756$ & Palpation, mammography & 4.68 & $3,053(0.24)$ \\
\hline
\end{tabular}


the stomach with liquid. A study by the Osaka Medical Center documented that these efforts have increased the pancreatic cyst detection rate from $70 \%$ to $92 \%$, consistently from the pancreas head to tail $(\mathrm{p}<0.001) .^{38}$ They screened 625 high-risk examinees every 6 months for 16 years, and detected PCs and intraductal papillary mucinous carcinomas (IPMCs) in 33 cases, or $0.3 \%$ per person year. Of these 33 cases, 18 cases (54.5\%) were UICCstage 0 or Ia. ${ }^{37}$

\section{Screening of HRIs and patients with pancreatic diseases}

In Japan, individuals who have only inherited and demographic risks but no abnormal pancreatic findings are excluded from pancreas screenings covered by national health insurance. These patients with image-detectable pancreatic diseases are instead clinically followed, bearing other risks in mind. In Korea, cases of IPMN are screened for PC risk, but magnetic resonance imaging (MRI) is not covered by the national insurance system. Consequently, the strategy for screening HRIs for PC may vary by country due to differences in a nation's mentality, technology, insurance system, and economics.

The international consensus guidelines for the management of IPMN and mucinous cystic neoplasms of the pancreas ${ }^{34}$ are widely used for screening of pancreatic cystic lesions and/or duct-ectatic lesions. The risk level of malignant transformation in branch-type IPMNs is judged by the findings of "highrisk stigmata," including obstructive jaundice, enhanced mural nodule ( $\geq 5 \mathrm{~mm}$ ), and MPD dilation ( $\geq 10 \mathrm{~mm}$ ). The risk level is further evaluated by the presence of "worrisome features," including cysts $\geq 3 \mathrm{~cm}$ in size, enhanced mural nodules $(<5$ $\mathrm{mm}$ ), thickened/enhanced cyst walls, MPD 5 to $9 \mathrm{~mm}$ in width, abrupt caliber change of the pancreatic duct with distal pancreatic atrophy, lymphadenopathy, cyst growth rate $\geq 5 \mathrm{~mm}$ over 2 years, and increased serum cancer antigen (CA19-9). Screening for each risk category is recommended with suitable modalities: computed tomography (CT) and MRI for a cyst size $<2 \mathrm{~cm}$ and endoscopic ultrasonography (EUS) or MRI+EUS for a cyst size $\geq 2 \mathrm{~cm}$. Appropriate screening intervals are initially 6 months for a cyst size $<2 \mathrm{~cm}$ and initially 3 to 6 months for a cyst size $\geq 2 \mathrm{~cm}$. The screening interval can be lengthened if no change is observed after following the international guidelines. ${ }^{34}$ The American Gastroenterological Association suggests that screening of pancreatic cystic lesions $<3 \mathrm{~cm}$ in size and without a solid component or a dilated pancreatic duct can be discontin- ued if the lesions are stable for $\geq 5$ years. ${ }^{39}$ Currently, several institutions have validated these criteria, while others have argued against them, ${ }^{40-42}$ and some recent papers contradict screening discontinuance. $^{43}$

The international consensus guidelines for Cancer of the Pancreas Screening $^{44}$ were established in 2011 in Baltimore by 49 international experts who had gathered to create a surveillance program for individuals with inherited risks of PC (Table 3). The guidelines target individuals with a greater than 5-fold RR or 5\% lifetime risk of $\mathrm{PC}$, with the goal of detecting and treating early stage (T1NOM0) PC and high-grade precursor lesions, including pancreatic intraepithelial neoplasm-3 (PanIN-3), high-grade IPMN, or IPMC. The guidelines recommend EUS and MRI for image modalities and a screening interval of 6 to 12 months for stable pancreatic lesions. ${ }^{44}$ Until recently, the outcomes of the surveillance were unsatisfactory, ${ }^{9}$ but the prognosis of HRIs who developed PCs was better with surveillance than without (3-year survival: $85 \%$ vs $25 \%, \mathrm{p}<0.001) .^{45}$

As already mentioned, general chronic pancreatitis (other than HP) also carries a risk of PC at some level. Guidelines for the management of chronic pancreatitis have been edited in many countries and internationally; however, statements regarding surveillance for early detection of PC vary among the guidelines (i.e., recommended, ${ }^{46,47}$ not mentioned, ${ }^{48-50}$ and not recommended $^{51}$.

\section{Image modalities for pancreas screening and pathologi- cal sampling}

Abdominal US, EUS, contrast-enhanced CT, and MRI/magnetic resonance cholangiopancreatography (MRCP) have all been used to determine the status of high-risk diseases. ${ }^{9,44}$ EUS is the most commonly used modality for screening, ${ }^{44}$ as it has the highest sensitivity for detecting minute PCs $(\leq 1 \mathrm{~cm}),{ }^{44,52}$ and its diagnostic ability improves by adding tissue-harmonic and/or contrast-enhanced images. ${ }^{52}$ Similarly, MRCP is highly regarded among experts because of its good visualization of duct-ectatic or cystic lesions like IPMNs, without radiation exposure. ${ }^{44}$ However, each modality has drawbacks and are contraindicated in some conditions; that is, contrast allergy or renal dysfunction for enhanced CT; claustrophobia and old metallic equipment installation for MRI/MRCP; necessity of conscious sedation and limited visualization of the pancreas in cases with a history of previous upper gastrointestinal surgery for EUS; and possible

Table 3. Screening Candidates with an Inherited Risk of Pancreatic Cancer

Individuals with $\geq 3$ affected relatives, with $\geq 1$ affected first-degree relative (FDR)

Individuals with $\geq 2$ affected FDRs with pancreatic cancer (PC), with $\geq 1$ affected FDR

Individuals with $\geq 2$ affected relatives with PC, with $\geq 1$ affected FDR

Peutz-Jeghers syndrome patients, regardless of family history of PC

Mutation carriers of $C D K N 2 A / p 16, B R C A, P A L B 2$ or mismatch repair genes (Lynch syndrome) with one affected FDR

$B R C A 2$ mutation carriers with two affected family members of PC 
blind areas affected by stones, obesity, and gastrointestinal gas for US.

During the follow-up of pancreatic lesions or precursors, pathological sampling is pursued upon the appearance of suspicious findings, such as pancreatic masses, enhanced nodules, pancreatic duct stenosis/narrowing, and focal pancreatic atrophy. Our diagnostic strategy is summarized in Fig. 1. In cases with a visible pancreatic mass of uncertain malignancy, EUSguided fine needle aspiration (EUS-FNA) is performed even for masses sized $\leq 1 \mathrm{~cm} .^{53-55}$ In cases of ductal lesions, either stenotic or ectatic, the preferred strategy is pancreatic juice extraction for cytology using endoscopic naso-pancreatic ductal drainage (ENPD), ${ }^{56,57}$ as the small PCs tended to extend intraductally when compared with the larger ones. ${ }^{58}$ An ENPD test should be avoided in cases with high risk of post-endoscopic retrograde cholangiopancreatography pancreatitis, such as those with rich pancreatic parenchyma, a normal MPD width, pancreatic divisum, secretion of highly viscous mucus which may stuck inside of ENPD, and so on. Presurgical EUS-FNA from the image-typical cancer lesions at the pancreas body and tail is controversial, because of the possibility of cancer seeding. ${ }^{59}$ Indications for these examinations should be discussed beforehand among experts at each institution.

\section{ACTUALLY DETECTED EARLY PANCREATIC CANCER IN JAPAN}

The Japan Study Group on the Early Detection of Pancreatic Cancer retrospectively analyzed the data of stage 0 and stage I PCs collected from 14 Japanese institutions and reported clinical profiles of these early PCs in January 2018. Among 51 cases of stage 0 PCs and 149 cases of stage I PCs, 51.5\% of the cases were incidentally detected by the abnormalities found during screening for other diseases, whereas the proportion of PCs detected by medical check-up only accounted for $17.0 \%{ }^{2}$ In these cases, symptoms appeared in only 25\%, and elevated levels of serum tumor markers (3\%) or pancreatic enzymes (6\%) were rarely found. ${ }^{2}$ These data indicate the necessity of screening by focusing on other medical fields and/or additional risk factors, and the need to pay more attention to incidental findings.

\section{TUMOR BIOMARKERS AND DEVICES POSSIBLY AP- PLIED FOR FUTURE SURVEILLANCE}

Much time has passed since the proposal of a strategy for early detection, but the outcomes are limited and reflect slow improvement. ${ }^{1,9}$ Today, serum CA19-9 is the most useful and efficient tumor marker in the clinical use, however is limited in the detection of early PC and is rather used as a prognostic tool. ${ }^{60}$ Consequently, epochal and innovative devices for the surveillance and diagnosis of PC are in urgent demand. For

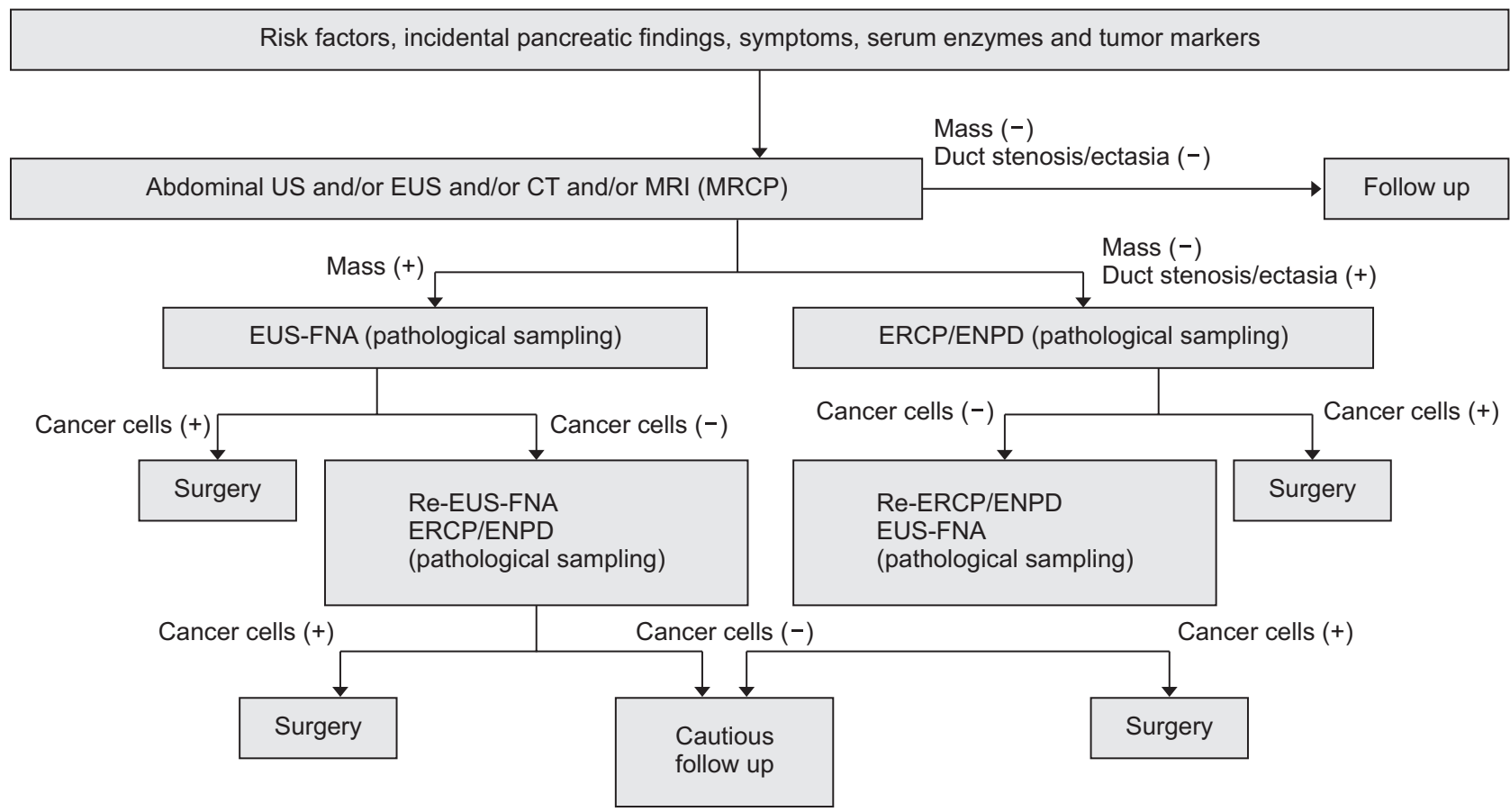

Fig. 1. Algorithm of the diagnosis and treatment of early pancreatic cancer.

US, ultrasonography; EUS, endoscopic ultrasonography; CT, computed tomography; MRI, magnetic resonance imaging; MRCP, magnetic resonance cholangiopancreatography; EUS-FNA, endoscopic ultrasonography guided-fine needle aspiration; ERCP, endoscopic retrograde cholangiopancreatography; ENPD, endoscopic naso-pancreatic drainage. 
instance, the price of genome analysis has rapidly decreased in recent years, ${ }^{61}$ and the accumulation of whole genome data will provide a more accurate assessment of the inherited risk of PC. Molecular analysis of samples easily obtainable during an annual health check-for instance, peripheral blood sample for analyses of circulating tumor DNA ${ }^{62,63}$ or microRNA ${ }^{64}$ in addition to serum CA19-9, duodenal fluid for analysis of mutant $T P 53^{65}$-will also improve the detection of very high-risk and early-stage PC. Development of molecular imaging techniques ${ }^{66}$ for clinical screening is expected, especially for PC, a silent killer.

\section{CONCLUSIONS}

Detection of early stage PCs will require improvements in each surveillance process; that is, the general health check system, selection of high-risk factors, image modalities, image evaluation, pathological sampling and diagnosis, and surgery. Clinicians also need to pay more attention to the incidental findings detected during non-surveillance procedures. Application of new technologies is essential to enable the early detection of PC.

\section{CONFLICTS OF INTEREST}

No potential conflict of interest relevant to this article was reported.

\section{AUTHOR CONTRIBUTIONS}

All authors reviewed the manuscript, and provided beneficial comments from the viewpoint of endoscopist, pathologist and surgeon. H.M drafted, and all other authors approved the final version of manuscript.

\section{ORCID}

Hiroyuki Matsubayashi https://orcid.org/0000-0002-7050-2351

\section{REFERENCES}

1. Egawa S, Toma H, Ohigashi H, et al. Japan Pancreatic Cancer Registry; 30th year anniversary: Japan Pancreas Society. Pancreas 2012;41:985-992.

2. Kanno A, Masamune A, Hanada K, et al. Multicenter study of early pancreatic cancer in Japan. Pancreatology 2018;18:61-67.

3. Tanno S, Nakano Y, Koizumi K, et al. Pancreatic ductal adenocarcinomas in long-term follow-up patients with branch duct intraductal papillary mucinous neoplasms. Pancreas 2010;39:36-40.

4. Choi SH, Park SH, Kim KW, Lee JY, Lee SS. Progression of unresected intraductal papillary mucinous neoplasms of the pancreas to cancer: a systematic review and meta-analysis. Clin Gastroen- terol Hepatol 2017;15:1509-1520.

5. Crippa S, Capurso G, Cammà C, Fave GD, Castillo CF, Falconi M. Risk of pancreatic malignancy and mortality in branch-duct IPMNs undergoing surveillance: a systematic review and metaanalysis. Dig Liver Dis 2016;48:473-479.

6. Tanaka S, Nakao M, Ioka T, et al. Slight dilatation of the main pancreatic duct and presence of pancreatic cysts as predictive signs of pancreatic cancer: a prospective study. Radiology 2010;254:965-972.

7. Lowenfels AB, Maisonneuve P, Cavallini G, et al. Pancreatitis and the risk of pancreatic cancer. International Pancreatitis Study Group. N Engl J Med 1993;328:1433-1437.

8. Raimondi S, Lowenfels AB, Morselli-Labate AM, Maisonneuve P, Pezzilli R. Pancreatic cancer in chronic pancreatitis; aetiology, incidence, and early detection. Best Pract Res Clin Gastroenterol 2010;24:349-358.

9. Matsubayashi H, Takaori K, Morizane C, et al. Familial pancreatic cancer: concept, management and issues. World J Gastroenterol 2017;23:935-948.

10. Klein AP, Brune KA, Petersen GM, et al. Prospective risk of pancreatic cancer in familial pancreatic cancer kindreds. Cancer Res 2004;64:2634-2638.

11. Masamune A, Kikuta K, Hamada S, et al. Nationwide survey of hereditary pancreatitis in Japan. J Gastroenterol 2018;53:152-160.

12. Rebours V, Boutron-Ruault MC, Schnee M, et al. Risk of pancreatic adenocarcinoma in patients with hereditary pancreatitis: a national exhaustive series. Am J Gastroenterol 2008;103:111-119.

13. Risch HA, Lu L, Wang J, et al. ABO blood group and risk of pancreatic cancer: a study in Shanghai and meta-analysis. Am J Epidemiol 2013;177:1326-1337.

14. Nakao M, Matsuo K, Hosono S, et al. ABO blood group alleles and the risk of pancreatic cancer in a Japanese population. Cancer Sci 2011;102:1076-1080.

15. Vasan SK, Hwang J, Rostgaard K, et al. ABO blood group and risk of cancer: a register-based cohort study of 1.6 million blood donors. Cancer Epidemiol 2016;44:40-43.

16. Larsson SC, Orsini N, Wolk A. Body mass index and pancreatic cancer risk: a meta-analysis of prospective studies. Int J Cancer 2007;120:1993-1998.

17. Calle EE, Rodriguez C, Walker-Thurmond K, Thun MJ. Overweight, obesity, and mortality from cancer in a prospectively studied cohort of U.S. adults. N Engl J Med 2003;348:1625-1638.

18. Guh DP, Zhang W, Bansback N, Amarsi Z, Birmingham CL, Anis $\mathrm{AH}$. The incidence of co-morbidities related to obesity and overweight: a systematic review and meta-analysis. BMC Public Health 2009;9:88.

19. Lynch SM, Vrieling A, Lubin JH, et al. Cigarette smoking and pancreatic cancer: a pooled analysis from the pancreatic cancer cohort consortium. Am J Epidemiol 2009;170:403-413.

20. Matsubayashi H, Maeda A, Kanemoto H, et al. Risk factors of familial pancreatic cancer in Japan: current smoking and recent onset of diabetes. Pancreas 2011;40:974-978. 
21. Iodice S, Gandini S, Maisonneuve P, Lowenfels AB. Tobacco and the risk of pancreatic cancer: a review and meta-analysis. Langenbecks Arch Surg 2008;393:535-545.

22. Ben Q, Xu M, Ning X, et al. Diabetes mellitus and risk of pancreatic cancer: a meta-analysis of cohort studies. Eur J Cancer 2011;47:1928-1937.

23. Chari ST, Leibson CL, Rabe KG, Ransom J, de Andrade M, Petersen GM. Probability of pancreatic cancer following diabetes: a population-based study. Gastroenterology 2005;129:504-511.

24. Lévy P, Jouannaud V, O'Toole D, et al. Natural history of intraductal papillary mucinous tumors of the pancreas: actuarial risk of malignancy. Clin Gastroenterol Hepatol 2006;4:460-468.

25. Kang MJ, Jang JY, Kim SJ, et al. Cyst growth rate predicts malignancy in patients with branch duct intraductal papillary mucinous neoplasms. Clin Gastroenterol Hepatol 2011;9:87-93.

26. Uehara H, Nakaizumi A, Ishikawa 0, et al. Development of ductal carcinoma of the pancreas during follow-up of branch duct intraductal papillary mucinous neoplasm of the pancreas. Gut 2008;57:1561-1565.

27. Kanno A, Satoh K, Hirota M, et al. Prediction of invasive carcinoma in branch type intraductal papillary mucinous neoplasms of the pancreas. J Gastroenterol 2010;45:952-959.

28. Kirkegård J, Mortensen FV, Cronin-Fenton D. Chronic pancreatitis and pancreatic cancer risk: a systematic review and meta-analysis. Am J Gastroenterol 2017;112:1366-1372.

29. Hao L, Wang LS, Liu Y, et al. The different course of alcoholic and idiopathic chronic pancreatitis: a long-term study of 2,037 patients. PLoS One 2018;13:e0198365.

30. Malinka T, Klein F, LE Thu T, et al. A bi-national analysis of 252 pancreatic resections for chronic pancreatitis with regard to incidental carcinoma sequence and overall postoperative outcome. Anticancer Res 2018;38:4947-4952.

31. Merdrignac A, Sulpice L, Rayar M, et al. Pancreatic head cancer in patients with chronic pancreatitis. Hepatobiliary Pancreat Dis Int 2014;13:192-197.

32. Chari ST, Mohan V, Pitchumoni CS, Viswanathan M, Madanagopalan N, Lowenfels AB. Risk of pancreatic carcinoma in tropical calcifying pancreatitis: an epidemiologic study. Pancreas 1994;9:62-66.

33. Yadav D, Lowenfels AB. The epidemiology of pancreatitis and pancreatic cancer. Gastroenterology 2013;144:1252-1261.

34. Tanaka M, Fernández-Del Castillo C, Kamisawa T, et al. Revisions of international consensus Fukuoka guidelines for the management of IPMN of the pancreas. Pancreatology 2017;17:738-753.

35. Japanese Cancer Society. 2016 Annual report [Internet]. Tokyo: Japanese Cancer Society [cited 2020 Jan 8]. Available from: http:// canscreen. ncc.go.jp/index.html.

36. Kumada K, Tanaka K, Miyashita Y, et al. Evaluation and measures of pancreatic cancer screening by ultrasonography in general medical checkups. Health Evaluation Promot 2014;41:259-267.

37. Ioka T, Katayama K, Ashida R. Current status of early diagnostic system of pancreatic cancer. Kan-Tan-Sui 2014;68:837-842.
38. Nakao M, Katayama K, Fukuda J, et al. Evaluating the ability to detect pancreatic lesions using a special ultrasonography examination focusing on the pancreas. Eur J Radiol 2017;91:10-14.

39. Vege SS, Ziring B, Jain R, Moayyedi P; Clinical Guidelines Committee; American Gastroenterology Association. American gastroenterological association institute guideline on the diagnosis and management of asymptomatic neoplastic pancreatic cysts. Gastroenterology 2015;148:819-822.

40. Okamura Y, Sano S, Sugiura T, et al. The 2012 International Consensus Guidelines of Intraductal Papillary Mucinous Neoplasms of the Pancreas (Fukuoka Criteria) Predict the Malignant Potential, Even in Actual Clinical Situations. Pancreas 2018;47:285-290.

41. Sugimoto M, Elliott IA, Nguyen AH, et al. Assessment of a revised management strategy for patients with intraductal papillary mucinous neoplasms involving the main pancreatic duct. JAMA Surg 2017;152:e163349.

42. Tsukagoshi M, Araki K, Saito F, et al. Evaluation of the international consensus guidelines for the surgical resection of intraductal papillary mucinous neoplasms. Dig Dis Sci 2018;63:860-867.

43. Imbe K, Nagata N, Hisada Y, et al. Validation of the American Gastroenterological Association guidelines on management of intraductal papillary mucinous neoplasms: more than 5 years of follow-up. Eur Radiol 2018;28:170-178.

44. Canto MI, Harinck F, Hruban RH, et al. International Cancer of the Pancreas Screening (CAPS) Consortium summit on the management of patients with increased risk for familial pancreatic cancer. Gut 2013;62:339-347.

45. Canto MI, Almario JA, Schulick RD, et al. Risk of neoplastic progression in individuals at high risk for pancreatic cancer undergoing long-term surveillance. Gastroenterology 2018;155:740-751. e2.

46. Schreyer AG, Jung M, Riemann JF, et al. S3 guideline for chronic pancreatitis - diagnosis, classification and therapy for the radiologist. Rofo 2014;186:1002-1008.

47. Ito $\mathrm{T}$, Ishiguro $\mathrm{H}$, Ohara $\mathrm{H}$, et al. Evidence-based clinical practice guidelines for chronic pancreatitis 2015. J Gastroenterol 2016;51:85-92.

48. Conwell DL, Lee LS, Yadav D, et al. American Pancreatic Association Practice Guidelines in chronic pancreatitis: evidence-based report on diagnostic guidelines. Pancreas 2014;43:1143-1162.

49. Frøkjær JB, Akisik F, Farooq A, et al. Guidelines for the Diagnostic Cross Sectional Imaging and Severity Scoring of Chronic Pancreatitis. Pancreatology 2018;18:764-773.

50. Löhr JM, Dominguez-Munoz E, Rosendahl J, et al. United European Gastroenterology evidence-based guidelines for the diagnosis and therapy of chronic pancreatitis (HaPanEU). United European Gastroenterol J 2017;5:153-199.

51. Delhaye M, Van Steenbergen W, Cesmeli E, et al. Belgian consensus on chronic pancreatitis in adults and children: statements on diagnosis and nutritional, medical, and surgical treatment. Acta Gastroenterol Belg 2014;77:47-65.

52. Kitano M, Kudo M, Yamao K, et al. Characterization of small solid 
tumors in the pancreas: the value of contrast-enhanced harmonic endoscopic ultrasonography. Am J Gastroenterol 2012;107:303310.

53. Yamao K, Sawaki A, Mizuno N, Shimizu Y, Yatabe Y, Koshikawa T. Endoscopic ultrasound-guided fine-needle aspiration biopsy (EUSFNAB): past, present, and future. J Gastroenterol 2005;40:10131023.

54. Matsubayashi H, Sasaki K, Ono S, et al. Pathological and molecular aspects to improve endoscopic ultrasonography-guided fine-needle aspiration from solid pancreatic lesions. Pancreas 2018;47:163-172.

55. Uehara H, Ikezawa K, Kawada N, et al. Diagnostic accuracy of endoscopic ultrasound-guided fine needle aspiration for suspected pancreatic malignancy in relation to the size of lesions. J Gastroenterol Hepatol 2011;26:1256-1261.

56. Matsubayashi H, Sasaki K, Nagata K, Kanemoto H, Kiuchi R, Ono H. Pancreatic carcinoma mimicking diffuse-type autoimmune pancreatitis: important diagnostic role of pancreatic juice cytology using endoscopic naso-pancreatic drainage. J Dig Dis 2012;13:287290.

57. Hanada K, Okazaki A, Hirano N, et al. Effective screening for early diagnosis of pancreatic cancer. Best Pract Res Clin Gastroenterol 2015;29:929-939.

58. Mastsubayashi H, Kasuya K, Ajioka Y, Itoi T, Yasuda A, Watanabe H. Pathology of early pancreatic cancer. Rinsho Kagaku 1995;31:318-326.
59. Minaga K, Takenaka M, Katanuma A, et al. Needle tract seeding: an overlooked rare complication of endoscopic ultrasound-guided fine-needle aspiration. Oncology 2017;93 Suppl 1:107-112.

60. O'Brien DP, Sandanayake NS, Jenkinson C, et al. Serum CA19-9 is significantly upregulated up to 2 years before diagnosis with pancreatic cancer: implications for early disease detection. Clin Cancer Res 2015;21:622-631.

61. Hayden EC. Technology: the $\$ 1,000$ genome. Nature 2014; 507:294-295.

62. Cohen JD, Javed AA, Thoburn C, et al. Combined circulating tumor DNA and protein biomarker-based liquid biopsy for the earlier detection of pancreatic cancers. Proc Natl Acad Sci U S A 2017;114:10202-10207.

63. Gall TMH, Belete S, Khanderia E, Frampton AE, Jiao LR. Circulating Tumor Cells and Cell-Free DNA in Pancreatic Ductal Adenocarcinoma. Am J Pathol 2019;189:71-81.

64. Schultz NA, Dehlendorff C, Jensen BV, et al. MicroRNA biomarkers in whole blood for detection of pancreatic cancer. JAMA 2014;311:392-404.

65. Kanda M, Sadakari Y, Borges M, et al. Mutant TP53 in duodenal samples of pancreatic juice from patients with pancreatic cancer or high-grade dysplasia. Clin Gastroenterol Hepatol 2013;11:719730.e5.

66. England CG, Hernandez R, Eddine SB, Cai W. Molecular imaging of pancreatic cancer with antibodies. Mol Pharm 2016;13:8-24. 